Ann. Biol. anim. Bioch. Biophys., 1978, 18 (2A), 249-257.

\title{
In vivo study of the effects of cycloheximide on gametogenesis in Eisenia foetida f. typica Sav. (Annelid Oligochaete)
}

\author{
par C. LATTAUD \\ Université Pierre-et-Marie-Curie, Laboratoire Sexualité et Reproduction des Invertébrés, \\ 4, Place Jussieu, 75230 Paris Cedex 05, France
}

\begin{abstract}
Summary. After cycloheximide injection in sexually active Eisenia foetida, only the male gonads showed 24 p. 100 sex reversal. When that drug was given for a short period of 9 days, protein synthesis was resumed in the reversed testes; oocytes in previtellogenesis were observed in these testes and in the posterior seminal vesicles. On the other hand, when cycloheximide treatment lasted longer (16 to 21 days), protein synthesis remained inhibited because only pachytene oocytes were visible in the reversed testes.

It is suggested that androgen hormone production was responsible since there is no ovary reversal after cycloheximide treatment.
\end{abstract}

\section{Introduction.}

Using organ culture, we previously studied the control of germ cell sex of Eisenia foetida f. typica Sav. (Oligochaete Lumbricidae). We demonstrated ovarian autodifferentiation (Lattaud, 1973) and showed that neurosecretion caused testis production of an androgenic substance The gonia evolved toward spermatogenesis or oogenesis, depending on whether or not they were affected by that androgen. Differentiation into ovaries or testes thus seemed assured by the fact that neurosecretion could not induce the ovary to synthesize androgen (Lattaud, 1974, 1975).

Relexans (1974) injected 100-200 $\mathrm{g} / \mathrm{ml}$ of cycloheximide into young, fasting worms 7 days, 25 days or 3 to 6 weeks old. This substance inhibits ribosome protein synthesis (Wettstein et al., 1964 ; Colombo ef al., 1965 ; Fautrez and Fautrez-Firlefyn, 1974). Several weeks after the treatment was withdrawn, about 19 p. 100 of the testes were found to be reversed into ovaries in worms which were 25 days or 3 to 6 weeks old when the injections were begun. These reversed testes presented female cells in meiotic prophase and developing oocytes. Only one case of reversed-ovary testis was observed in which spermatic follicles were present. This reversal is not significant because a control also showed ovarian masculinization after several weeks of fasting.

The results of Relexans agree with ours because they may be interpreted as direct or indirect inhibition of the androgen synthesis controlling spermatogenesis. 
In this report, we have studied cycloheximide action in different conditions. We used sexually active worms which were not fasting since fasting itself modifies gametogenetic activity.

\section{Material and methods.}

Our experiments were carried out on sexually active Eisenia foetida 3 or 4 months old. We injected 4 to $5 \mu \mathrm{l}$ of cycloheximide in 100 or $200 \mu \mathrm{g} / \mathrm{ml}$ doses of physiological serum (Holtfreter solution at 8.77 p. 100) into the 12 th segment of previously anesthetized worms ; segment 12 is situated between the testicular and ovarian regions (fig. 1). A total of 54 worms was treated : 16 were given cycloheximide in a $100 \mu \mathrm{g} / \mathrm{ml}$ dose and 38 in a $200 \mu \mathrm{g} / \mathrm{ml}$ dose. Due to coelomic fluid pressure, it was difficult to accurately estimate the quantity of the solution injected because some leaked out where the needle entered. The injections were repeated every 2 or 3 days for 9,16 or 21 days.

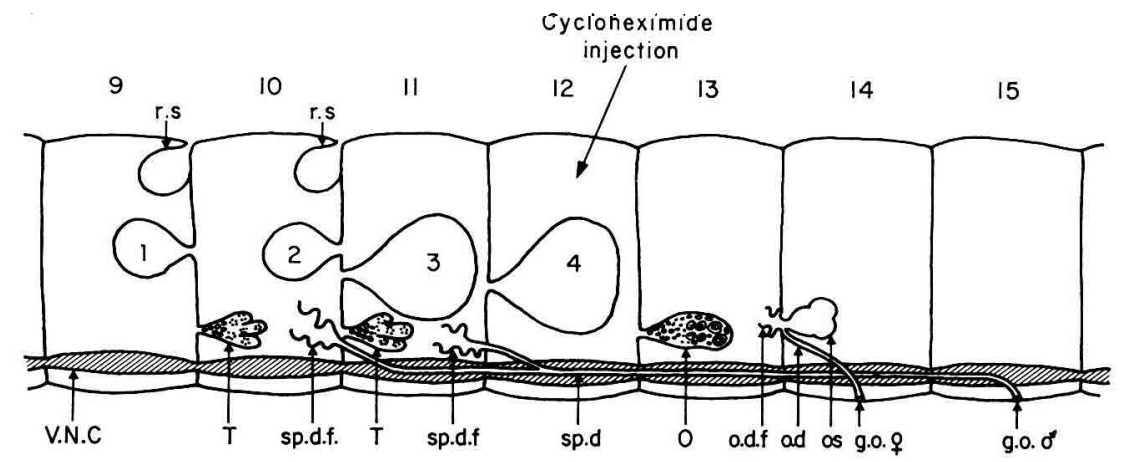

FIG. 1. - Localization of the site of cycloheximide injection in Eisenia fœida. V. N. C., ventral nervous chain ; O, ovary; O. d., oviduct ; os, ovisac; g. o., genital openings ; o. d. f., oviduct fimbria ; sp. d. f., spermiduct fimbria ; s. r., seminal receptacle ; sp. d., spermiduct ; T, testis ; 1 - 2 - 3 - 4 , seminal vesicles.

Gametogenesis was arrested after 1 to 5 weeks of fasting in the sexually active Eisenia foetida. When 5 weeks of fasting are followed by 10 days of re-feeding, there is no spermatogenesis in the ovaries. On the other hand, some testis gonia develop into oocytes (Herlant-Meewis, 1962, 1966 ; Lattaud, 1971). Thus, our worms were put back into thoroughly dampened earth 7 to $8 \mathrm{hrs}$ after each cycloheximide injection and at the end of the treatment to avoid the effect of fasting on gametogenesis. They were fixed 2 or 3 weeks after the treatment was withdrawn.

We also injected Holtfreter physiological solution at 8.77 p. 100 and containing no cycloheximide, into control worms from the same breeding colony as the treated subjects.

\section{Results.}

Using histological techniques, we checked the digestive tract of Eisenia foetida given cycloheximide to be sure that it was not empty. We were thus certain that the worms did not fast during the treatment or in the weeks following. 
Histological sections of ovaries, testes and seminal vesicles of controls showed that gamelogenesis was not affected.

Histological study of gonads and seminal vesicles of cycloheximide-treated Eisenia foetida showed the following results:

1. Testes.

Table 1 shows the number of ovotestes in 54 worms. The stages of oogenesis are noted in relation to cycloheximide dose and length of treatment. It was noted that the worms had 1, 2, 3 or 4 reversed-testis ovaries.

TABLE 1

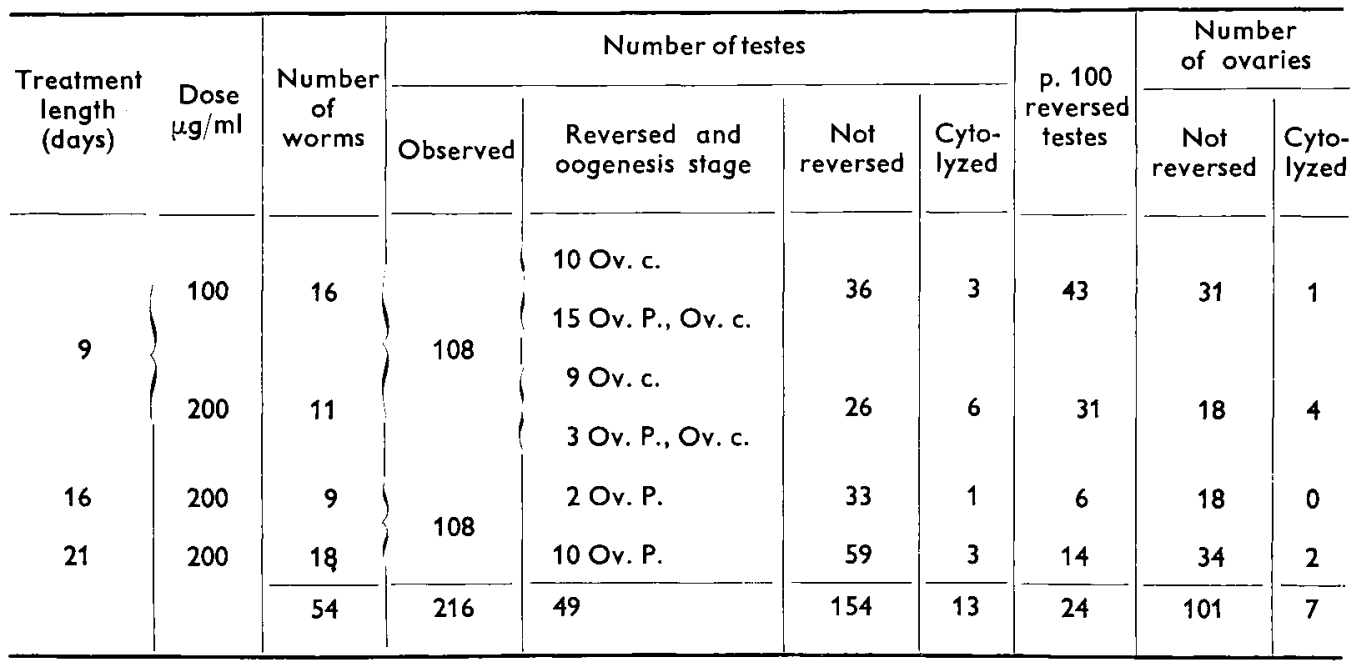
visible).

Ov. c., developing oocytes (chromosomes invisible) : Ov. P., oocytes at pachyłene stage (chromosomes

After 16 or 21 days of cycloheximide injection, followed by 2 or 3 weeks of withdrawal, 12 testes out of 108 presented oocytes I with visible chromosomes at the beginning of meiotic prophase. These oocytes usually had maximum chromosome condensation at one of the nuclear poles, characteristic of the pachytene stage. The oocytes were found in different regions of the reversed testis. Isogenic groups of 4 to 12 oocytes in premeiosis were seen between the protogonial zone and spermatic follicles (PI. I, fig. 1) or surrounded by spermatic follicles of the distal region of the testis. No developing oocyte was found in the 12 reversed-testis ovaries. After 16 or 21 days of cycloheximide injection at a dose of $200 \mu \mathrm{g} / \mathrm{ml}$, the reversal percentage is thus low, not exceeding 6 and 14 p. 100, respectively.

After 9 days of cycloheximide treatment, followed by 2 or 3 weeks of withdrawal, no oocyte in pachytene stage was found in 19 testes out of the 108 studied. On the other hand, developing and older oocytes were noted in the testis-reversed ovaries. We found:

- female inclusions constituted of numerous developing oocytes, situated laterally in 
PLATE
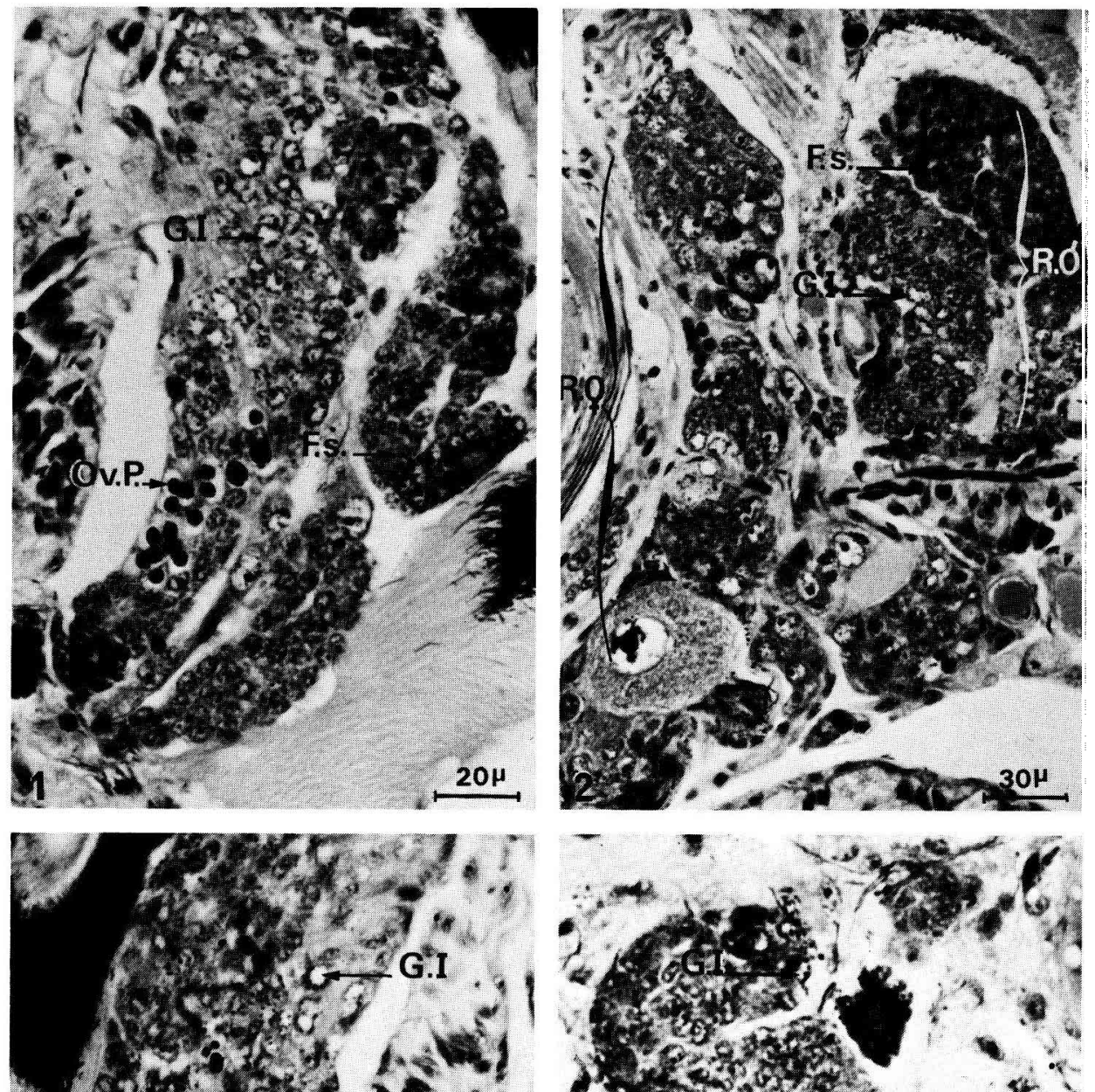

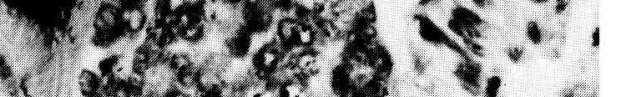

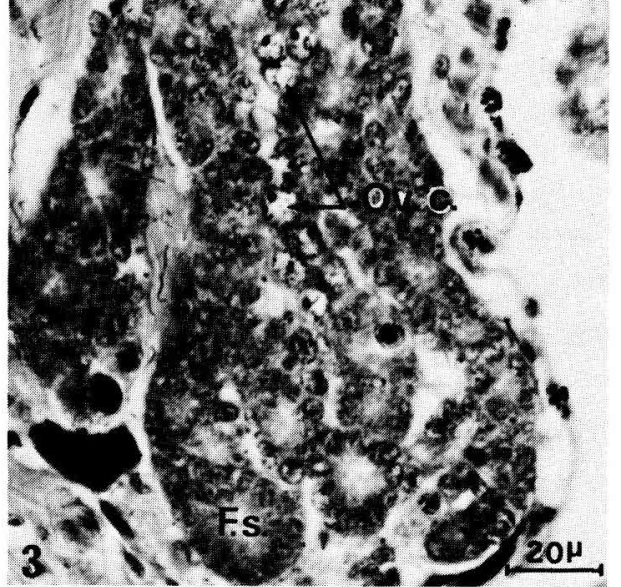

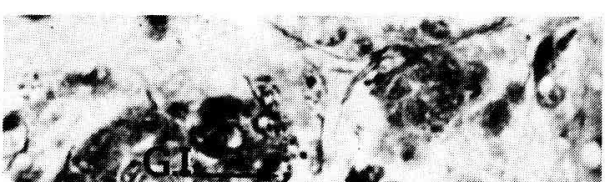

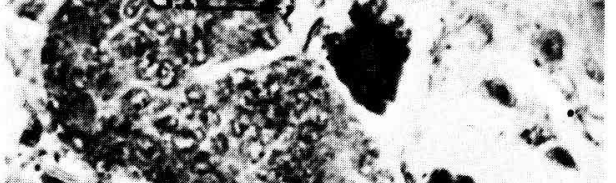
$6 y^{2}+2 x^{2}+x^{2}$

the spermatic follicle region. The larger oocytes, surrounded by follicular cells, were localized in the most distal region of the testis ;

- plurilobate testes with one lobe presenting total sex reversal (PI. I, fig. 2) ;

- developing oocyte cords penetrating between male gonad cells from the testis proximal zone to its distal extremity. We counted as many as 9 oocytes (PI. I, fig. 3) ; - 3 cases where there was only 1 developing oocyte having little cytoplasm and a diameter of less than $40 \mu$; it was found among the spermatic follicles of the testis ;

- young oocytes situated among the spermatic follicles of the distal region of the testis. These oocytes were usually grouped ; sometimes their arrangement resembled that of the spermatic follicle (PI. I, fig. 4). They are termed oocyte follicles hereafter.

After 9 days of cycloheximide injection, followed by 2 or 3 weeks of withdrawal, 18 testes out of 108 presented not only oocytes at the pachytene stage, but also developing oocytes. These female cells usually formed a cord extending from the proximal zone of the testis, rich in pachytene-stage oocytes, to its distal extremity (PI. II, fig. 1). This region shows several large oocytes undergoing considerable cytoplasmic development ; they are surrounded by follicular cells. After 9 days of cycloheximide treatment at doses of 100 or $200 \mu \mathrm{g} / \mathrm{ml}$, the percentage of reversed testes reaches 43 and 31 p. 100 , respectively.

In all, 49 cases of 216 testes were reversed into ovaries. Taking into account 13 cases of cytolysis, reversal percentage reached 24 p. 100 . No testis presented total sex reversal.

\section{Seminal vesicles.}

After 9 days of cycloheximide injection, followed by 2 or 3 weeks of withdrawal, 9 out of 54 worms presented feminization of 2 or 4 posterior seminal vesicles. This reversal was characterized by the presence of 8 to 16 developing young oocytes. The mean cell diameter of these was 8 to $16 \mu$; they showed a thin cytoplasmic crown and formed oocyte follicles surrounded by follicles developing synchronically toward the male. One or 2 older oocytes, 35 to $80 \mu$ in diameter, were noted; they were located

\section{PLATE I}

FIG. 1. - $x$-section of reversed-festis ovary after 21 days of cycloheximide treatment followed by 2 weeks of withdrawal. Oocytes in pachytene stage with visible chromosomes are seen between protogonia and spermatic follicles. No developing oocyte can be seen.

FIG. 2, 3, 4. - x-sections of reversed-testis ovaries after 9 days of cycloheximide treatment followed by 3 weeks of withdrawal. No pachytene-stage oocyte is seen. Developing oocytes are visible.

FIG. 2. - Total sex reversal of one of the festis lobes.

FIG. 3. - Cord of 9 developing oocytes penetrating between spermatic follicles.

FIG. 4. - Oocyte follicle constituted of 5 developing oocytes and situated between spermatic follicles of the distal region of the testis.

F. ov., oocyte follicle ; F. s., spermatic follicle ; G. I., protogonia ; Ov. c., developing oocyte ; Ov. P., oocyte at pachytene stage ; R. $\sigma^{\star}$, male region ; R., , female region. 
among the young oocytes of the oocyte follicles or outside these follicles (PI. II, fig. 2).

An oocyte follicle was found in the cœlom of the testicular segment 10 or 11 (PI. II, fig. 3) of 4 worms presenting an anterior or posterior testis reversal associated with feminization of 2 or 4 posterior seminal vesicles. In these 4 worms, the intracolomic oocyte follicle, constituted of 4 to 12 young developing oocytes, was situated near the distal region of the testis-reversed ovary.

In the distal lobe of the reversed testis, we noted a group of young oocytes ready to be hatched. In 3 worms, an intracolomic oocyte follicle was found in the zone adjacent to a testis presenting no reversal (PI. II, fig. 4).

\section{Ovaries.}

After 9, 16 or 21 days of cycloheximide treatment, no reversal was noted in the 108 ovaries studied, and oogenesis proceeded normally.

\section{Discussion and conclusion.}

The present study of the effect of inhibitors such as cycloheximide on gonial evolution during gametogenesis shows that that drug only affects spermatogenesis. Reversal of testes into ovaries occurred with 3 different lengths of treatment $(9,16$ or 21 days) and with an injected dose of either 100 or $200 \mu \mathrm{g} / \mathrm{ml}$. When the treatment lasted 16 or 21 days at a dose of $200 \mu \mathrm{g} / \mathrm{ml}$, only pachytene-stage oocytes with visible chromosomes were observed, and reversal percentage was low (6 p. 100 after 16 days of injection ; 14 p. 100 after 21 days). On the other hand, when the cycloheximide treatment was short (9 days), reversal percentage was higher (43 and 31 p. 100 for doses of 100 and $200 \mu \mathrm{g} / \mathrm{ml}$, respectively), oogenesis was more advanced, and oocytes in previtellogenesis were seen. In that case, it is probable that the effects of the substance disappeared much quicker and new protein syntheses occurred, thus permitting oocyte cytoplasma to form. While taking into account the wide variation in percentages, depending on experimental conditions (length of treatment and dose), we can consider that the overall percentage of reversed-testis ovaries in 54 worms repeatedly injected with

\section{PLATE ॥}

9 days of cycloheximide treatment followed by 3 weeks of withdrawal.

FIG. 1. - x-section of reversed-festis ovary. Note the cord composed of oocytes at pachytene stage and developing oocytes, extending from the proximal zone of the testis to the distal region.

FIG. 2. - $x$-section of seminal vesicle showing 2 oocytes of 40 and $60 \mu$ diameter situated among follicles in different stages of spermatogenesis.

FIG. 3. - Oocyte follicle constituted of 11 developing young oocytes and located in the coelom of festis segment 10.

FIG. 4. - Intracoelomic oocyfe follicle situated near the distal region of a testis having no female cells.

F. ov., oocyte follicle ; F. s., spermatic follicle ; G. I., protogonia ; Ov. c., developing oocyte ; Ov. P., oocyte at pachytene stage. 
PLATE II

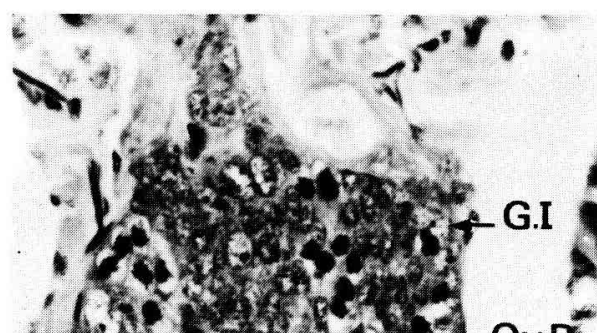

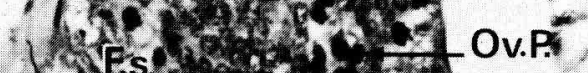

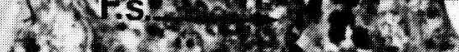

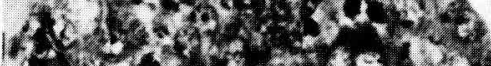

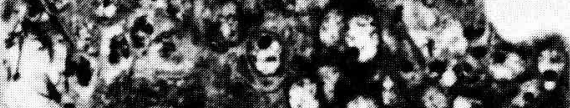

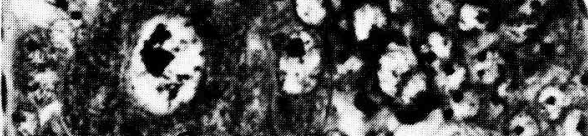

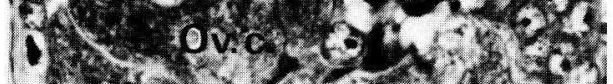

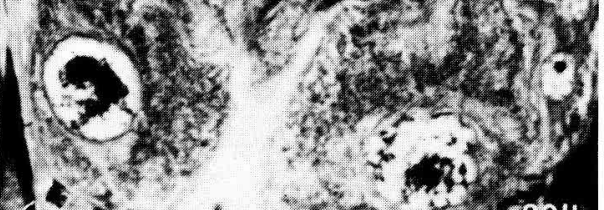
1. है?

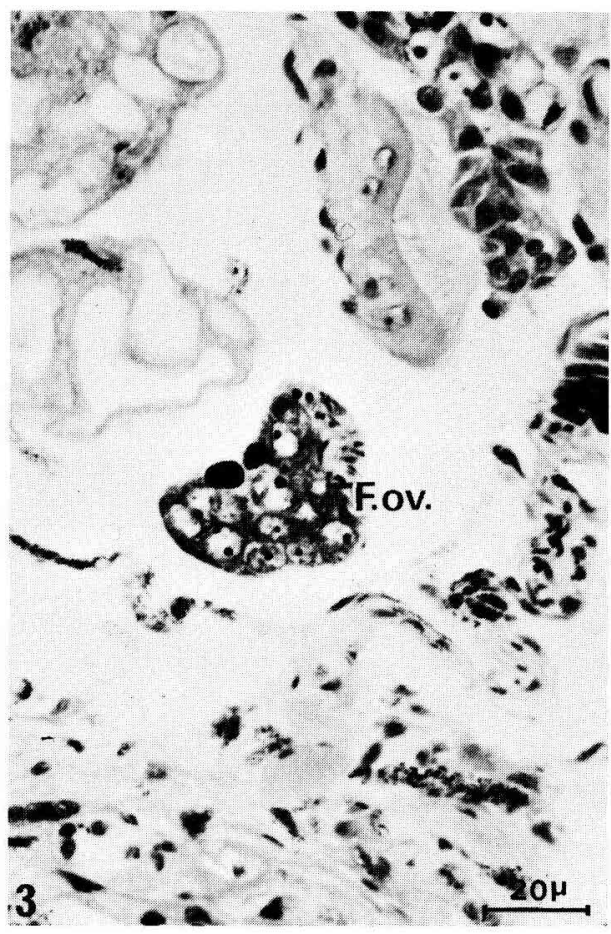

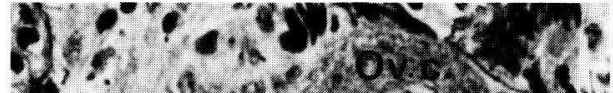

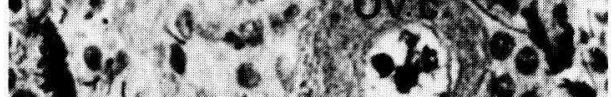

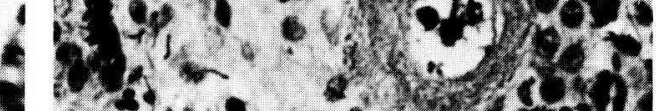

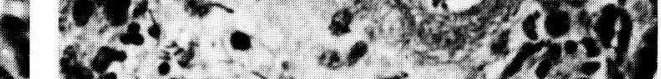

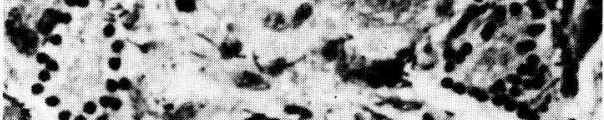
i. (2)

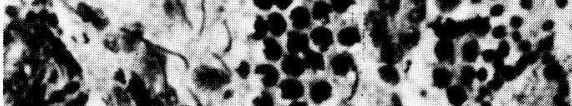

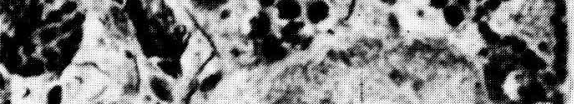

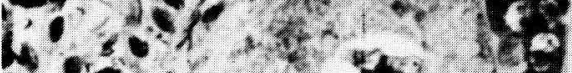

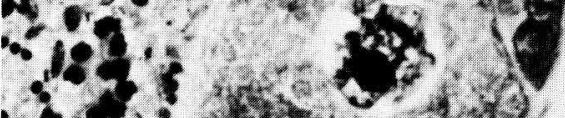

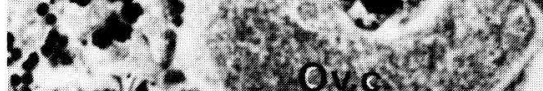

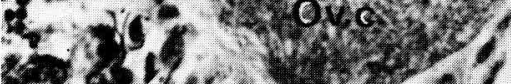

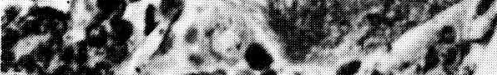

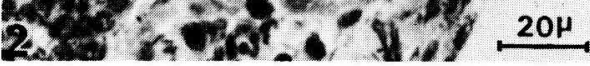

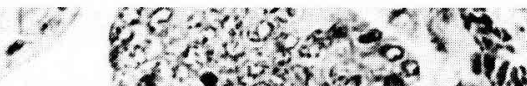

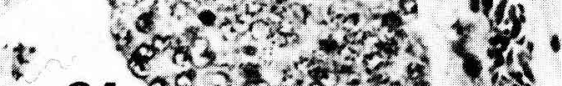

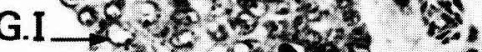

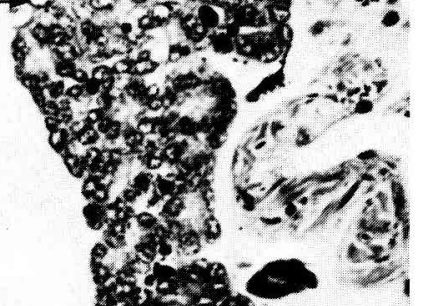<smiles>[Li][13CH3]</smiles>

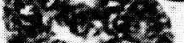
(6) th

Fovig tof Fs. 4. 130\% 
cycloheximide, reached 24 p. 100 . Besides reversed-testis ovaries, we noted feminization of 2 or 4 anterior and posterior seminal vesicles.

On the other hand, the ovaries presented no sex reversal. This result is very signifiant, considering that 108 ovaries were treated with cycloheximide.

An interesting point is the origin of the oocyte follicles seen in the feminized seminal vesicles and in the coelom of testis segment 10 or 11. In 4 cases, intracclomic oocyte follicles were found near the distal region of testis-reversed ovaries. These follicles thus seem to originate from reversed testes. They fall into the cœlom when the splanchnopleural gonad wall ruptures under gonial multiplication. In 3 worms, an intracœlomic oocyte follicle was seen near a testis showing no female cell. This follicle probably originated from a group of testicular protogonia which evolved synchronically toward the female. Some intracœlomic female follicles continued their evolution into seminal vesicles, because we have noted feminization of some of them. One or 2 isolated oocytes, surrounded by the male follicles of a seminal vesicle, could result from the evolution of 1 or 2 testicular gonia toward the female.

Our results are comparable to those of Relexans, but our interpretations differ. He believes that two inducers, male and female, control sex differentiation, and that testis reversal would be due to the presence of an inducer of the sex opposite to the presumptive sex. Protein synthesis inhibitors could cause active reversal of inducer synthesis in somatic cells. We believe that when cycloheximide treatment does not last longer than 9 days, previtellogenesis commences. The ovarian function is then completely established and sex reversal is total. We would suggest that androgen hormone production is responsible since there is no ovary reversal after cycloheximide treatment.

Reçu en juin 1977.

Accepté en octobre 1977.

Résumé. Après injection de cycloheximide chez Eisenia foetida en période d'activité sexuelle, seules les gonades mâles présentent un certain pourcentage d'inversion sexuelle (24 p. 100). Quand la durée d'application de cette drogue est courte ( 9 jours), il y a reprise des synthèses protéiques dans les testicules inversés ; en effet, des ovocytes en prévitellogenèse sont visibles dans ces testicules et dans les vésicules séminales postérieures. En revanche, quand la durée du traitement à la cycloheximide se prolonge (16 à 21 jours), les synthèses protéiques restent bloquées puisque seuls des ovocytes au stade pachytène sont observés dans les testicules inversés. On peut émettre l'hypothèse que la production d'hormone androgène serait en cause, puisque les ovaires ne s'inversent pas après traitement par la cycloheximide.

\section{References}

COLOMBO B., FELICETTI L., BAGLIONI C., 1965. Inhibition of protein synthesis by cycloheximide in rabbit reticulocytes. Biochem. biophys. Res. Comm., 18, 391-395.

FAUTREZ J., FAUTREZ-FIRLEFYN N., 1974. Contribution à l'étude des effets de la cycloheximide sur l'œuf en maturation et en segmentation. (Observation sur Artemia salina.) Arch. Bio. Bruxelles, 85, 183-200.

HERLANT-MEEWIS H., 1962. Influence de la nutrition sur la reproduction chez Eisenio fœtida. C. R. Acad. Sci. Paris, 255, 2187-2188.

HERLANT-MEEWIS H., 1966. Evolution de l'appareil génital d'Eisenia fœetida au cours du jeûne, de la régénération postérieure et à la suite de l'ablation des ganglions nerveux. Ann. Soc. r. Zool. Belg., 96, 189-240. 
LATTAUD C., 1971. Evolution des testicules et des vésicules séminales chez les Oligochètes Lumbricidae Eisenia foefida et Lumbricus terrestris, au cours du jeûne, suivi ou non de re-nutrition. C. R. Acad. Sci. Paris, Sér. D, 272, 319-322.

LATTAUD C., 1973. Autodifférenciation ovarienne chez l'annélide Oligochète Eisenia fæatida $f$. typica Sav. démontrée au moyen de la culture organotypique. C. R. Acad. Sci. Paris, Sér. D, 276, 1737-1740.

LATTAUD C., 1974. Ełude en culture organotypique du contrôle du sexe des gamétogenèses chez l'annélide Eisenia foetida f. typica Sav. ; mise en évidence d'une action androgène des tissus testiculaires en présence du système nerveux central. C. R. Acad. Sci. Paris, Sér. D, 279, 935-938.

LATTAUD C., 1975. Study of sex control of gamatogenesis by organ culture in the Oligochaete Annelid Eisenia foetida f. typica Sav., 64-71. In R. REINBOTH., Intersexuality in the animal kingdom, Springer-Verlag, Berlin, Heidelberg, New York.

RELEXANS J. C., 1974. Recherche expérimentale des facteurs de la différenciation sexuelle chez l'hermaphrodite simultané Eisenia foetida Sav. (Oligochète Lombricidé). Thèse de Doct. ès Sci. Nat., Bordeaux.

WETTSTEIN F. O., NOLL H., PENMAN S., 1964. Effect of cycloheximide on ribosomal aggregates engaged in protein synthesis in vifro. Biochim. biophys. Acta, 87, 525-528. 